\title{
Tempat Pembuangan Akhir (TPA) Kaliori Sebagai Wisata Edukasi Di Kabupaten Banyumas Dengan Penekanan Desain Pada Pengolahan Sekuen Ruang
}

\author{
Astya Jayanti Kurnia Santoso, MDE Purnomo, Sumaryoto \\ Program Studi Arsitektur \\ Universitas Sebelas Maret Surakarta \\ Email : astya.jks@gmail.com
}

\begin{abstract}
Tempat Pembuangan Akhir (TPA) Kaliori is one of landfills in Banyumas whose sanitary landfill system which is a well-planned waste management system. TPA Kaliori is one of the government's efforts in improving the waste management system in Indonesia. TPA Kaliori is initiated into educational tourism destination by Banyumas regent period 2013 - 2018. Educational tourism in TPA Kaliori is expected to be a means of education about waste. To be presented communicatively based on order/sequence is the key to well-delivered information. The issue is how to design waste management facilities as well as educational tourism with the sequence based in waste treatment process. The objective of this scheme is to get the design of TPA Kaliori as a facility for waste processing and educational tourism activities with an emphasis on designing sequence of spaces. The method used is a method of architectural design with an emphasis on the sequence of spaces. The results obtained, is the design of TPA Kaliori as waste treatment facilities and educational tourism with an emphasis on designing sequence of spaces. The spaces are connected by a circulation that will automatically guide the user to follow a sequence.
\end{abstract}

Keywords: educational tourism, landfill, sequence of space, TPA Kaliori, waste management

\section{PENDAHULUAN}

Salah satu dampak pertumbuhan penduduk adalah penumpukan sampah yang terus meningkat. Pertumbuhan sampah berbanding lurus dengan pertumbuhan penduduk. Indonesia dengan penduduk sekitar 327 juta jiwa dalam sehari dapat menghasilkan sampah sebanyak 73 juta ton per tahun atau setara dengan 200 ribu ton per hari (liputan6.com, 2014). Sistem pengolahan sampah di Indonesia umunya dilakukan secara sentralisasi dengan tujuan akhir ke Tempat Pembuangan Akhir (TPA). Berdasarkan hasil studi di tahun 2008 yang dilakukan beberapa kota, rasio sampah yang diangkut dan ditimbun di TPA adalah sebesar 69\% (Damanhuri,2008). Sayangnya, dengan rasio sebesar itu, sampah yang ditimbun belum diolah dengan baik pada kebanyakan TPA di Indonesia. 90\% TPA masih dioperasikan dengan sistem terbuka (open dumping). Open dumping adalah sistem pembuangan paling sederhana dimana sampah dibuang begitu saja dalam sebuah tempat pembuangan akhir tanpa perlakuan lebih lanjut.
Sistem open dumping ini menimbulkan banyak permasalahan seperti timbulnya bau busuk, munculnya berbagai penyakit dan terkontaminasinya air tanah.

Berbagai upaya dilakukan oleh pemerintah pusat maupun daerah untuk menanggulangi masalah sampah tersebut. Pada Mei 2008, pemerintah mengesahankan Undang-Undang Nomor 18 Tahun 2008 tentang Pengelolaan Persampahan yang mewajibkan pemerintah daerah menutup TPA dengan sistem open dumping. Selain mengesahkan undang-undang tersebut, pemerintah berperan aktif dalam perbaikan sarana dan prasarana TPA di berbagai daerah. Salah satu TPA yang mengalami perbaikan sistem adalah TPA Kaliori di Banyumas. TPA ini tidak lagi menggunakan sistem open dumping melainkan sanitary landfill sehingga bisa dikatakan sistem pengolahan pengolahan sampahnya sudah lebih baik.

Pada sistem sanitary landfill, terdapat saluran sanitasi air lindi dengan sistem pengolahan yang terencana. Di TPA Kaliori ini 
terdapat pengolahan gas metan menjadi biogas dan pengolahan sampah organik menjadi pupuk kompos. Biogas yang dihasilkan disalurkan ke rumah warga sekitar TPA. Pupuk kompos yang dihasilkan di TPA ini kemudian akan disalurkan ke taman-taman kota dan taman di kantor Pemda.

TPA Kaliori ini digagas menjadi TPA wisata edukasi lingkungan oleh Bupati Banyumas periode 2013 - 2018, Ir. Ahmad Hussein. Wisata Edukasi di TPA kaliori ini diharapkan dapat menjadi sarana pendidikan mengenai lingkungan khususnya tentang sampah. Penyajian secara komutikatif menjadi kunci tersampaikannya informasi yang ingin diberikan. Masyarakat yang berkunjung ke TPA Kaliori dapat belajar secara langsung dengan cara yang menyenangkan/bersifat rekreatif mengenai berbagai metode pengolahan sampah dan diharapkan dapat mengaplikasikannya dalam lingkungan masing-masing.

Kegiatan pengolahan sampah pada TPA Kaliori merupakan sebuah proses yang berjalan secara berurutan dimulai dari sampah datang hingga tahap akhir pengolahan. Agar pengunjung dapat memahami keseluruhan proses, maka diperlukan alur/urutan dalam proses edukasi tentang sampah sesuai dengan urutan pemrosesan sampah. Dengan begitu, informasi/pengetahuan dapat tersampaikan dengan lebih komunikatif.

\section{METODE}

Untuk mencapai tujuan dan sasaran yang telah dirumuskan berdasar rumusan masalah dan persoalan, metoda penyelesaian terdiri dari:

1. Ide dimulai dari gagasan Bupati Banyumas untuk menjadikan TPA Kaliori sebagai TPA Wisata Edukasi.

2. Pemahaman awal dalam lingkup arsitektur tentang objek yang direncana dimulai dari mendefinisikan dan membuat pemahaman menganai objek yang direncanakan.

3. Penelusuran dan merumuskan permasalahan.

4. Kajian pustaka sebagai referensi baik dari sumber teoritik, preseden maupun pengetahuan empirik.

5. Analisis data dan informasi.
6. Analisis pendekatan gambaran umum dan spesifik objek yang akan dirancang dan perumusan konsep perencanaan (building concept atau concept of building).

7. Analisis pendekatan rumusan konsep perancangan (programming, design criteria and performancy of a design concept) yang lebih spesifik tentang objek yang akan dirancang.

8. Transformasi rancang bangun arsitektur dan rancangan awal (pra rancangan/ preliminery design.

\section{ANALISIS}

\subsection{Analisis Peruangan}

Kebutuhan ruang yang muncul merupakan pertimbangan dari kegiatan yang dilakukan pada TPA Kaliori.

Tabel 1.Kebutuhan Ruang Pada TPA Kaliori

\begin{tabular}{|c|c|c|}
\hline PELAKU & KEGIATAN & RUANG \\
\hline \multirow{7}{*}{$\begin{array}{c}\text { Pengelola } \\
\text { TPA }\end{array}$} & Datang-pergi & $\begin{array}{l}\text { Side/service } \\
\text { entrance }\end{array}$ \\
\hline & Parkir & Area parkir \\
\hline & Bekerja & $\begin{array}{l}\text { R. pengelola, R. } \\
\text { staff, front } \\
\text { office, pos } \\
\text { satpam, area } \\
\text { pengolahan } \\
\text { sampah } \\
\end{array}$ \\
\hline & Rapat & R. rapat \\
\hline & Istirahat & Pantry \\
\hline & MCK & Toilet \\
\hline & Ibadah & Musholla \\
\hline \multirow{6}{*}{ Pengunjung } & Datang-pergi & $\begin{array}{l}\text { Side/service } \\
\text { entrance }\end{array}$ \\
\hline & Parkir & Area parkir \\
\hline & $\begin{array}{l}\text { Menunggu, } \\
\text { mendapat } \\
\text { informasi }\end{array}$ & $\begin{array}{l}\text { Area penerima, } \\
\text { Waste Edu } \\
\text { Centre }\end{array}$ \\
\hline & $\begin{array}{l}\text { Melihat } \\
\text { proses } \\
\text { pengolahan } \\
\text { sampah }\end{array}$ & $\begin{array}{l}\text { Area dropping, } \\
\text { area sortir, } \\
\text { rumah kompos, } \\
\text { area pengolahan } \\
\text { air lindi }\end{array}$ \\
\hline & $\begin{array}{l}\text { Membuat } \\
\text { kerajinan }\end{array}$ & Area workshop \\
\hline & Makan & Cafe \\
\hline
\end{tabular}




\begin{tabular}{|l|l|l|}
\hline \multirow{2}{*}{$\begin{array}{l}\text { Belanja } \\
\text { produk dan } \\
\text { suvenir }\end{array}$} & Kaliori Shop \\
\cline { 2 - 3 } & Beristirahat & Shelter \\
\cline { 2 - 3 } & Ibadah & Musholla \\
\cline { 2 - 3 } & MCK & Toilet \\
\hline
\end{tabular}

Pada Tabel 1. terlihat kebutuhan peruangan menurut pengguna dan kegiatannya.

\subsection{Analisis Pencapaian}

Pencapaian ke dalam TPA harus mudah dilihat dan diakses serta adanya pemisahan akses keluar-masuk antara pengunjung dan pengelola agar tidak terjadi crossing.

1. Tujuan: menentukan main entrance, menentukan service entrance

2. Dasar Pertimbangan: sirkulasi tapak yang mudah diakses, arus kendaraan tingkat keamanan dan kenyamanan, menghindari crossing.

3. Proses analisis

Terdapat dua main entrance, yaitu: Main Entrance $1\left(\mathrm{ME}_{1}\right)$

Sebagai akses kendaraan pengangkut sampah dengan menyesuaikan eksisting jalan/ akses di dalam tapak untuk kemudahan sirkulasi dropping sampah.

Main Entrance $2\left(\mathrm{ME}_{2}\right)$

Sebagai akses pengunjung memasuki kawasan TPA Kaliori

\section{Side Entrance (SE)}

Tidak mengganggu keberadaan ME. Diperuntukkan sebagai sirkulasi pengelola dan servis.

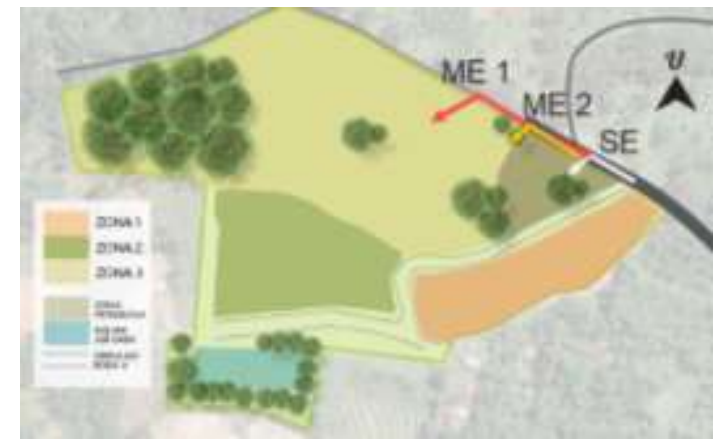

Gambar 1. Pola Pencapaian Pada Tapak

\subsection{Analisis Pemintakatan (Penzoningan)}

Pemintakatan dilakukan berdasarkan sifat kegiatan, kebutuhan ruang serta urutan berdasarkan proses pengolahan sampah.
1. Tujuan: Menentukan mintakan yang seusai dengan alur pengolahan sampah agar memudahkan dalam kegiatan operasional TPA maupun kegiatan wisata edukasi

2. Dasar pertimbangan: analisis peruangan, dan analisis pengolahan tapak,

3. Proses analisis: menentukan pemintakan berdasarkan urutan pemrosesan sampah dan alur kegiatan pengunjung wisata seperti yang terlihat pada Gambar 2.

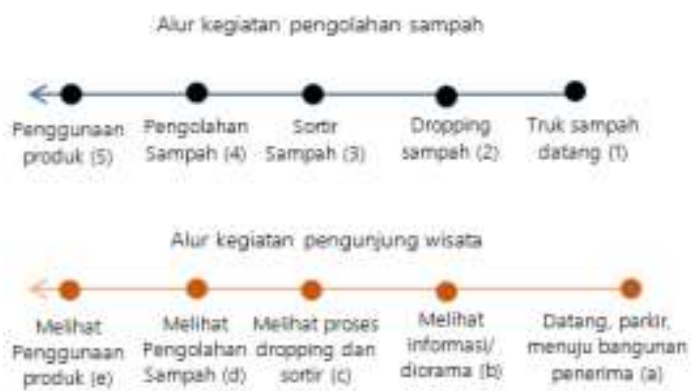

Gambar 2. Urutan Pengolahan Sampah

Alur pengolahan sampah dan alur kegiatan pengunjung wisata kemudian diterapkan pada tapak dengan mempertimbangkan kondisi eksisting. Langkah awal adalah menentukan mintakan yang menjadi pusat dari pengolahan sampah sebagai inti kegiatan TPA kemudian penyesuaian dari mintakan-mintakan lainnya (Gambar 3).

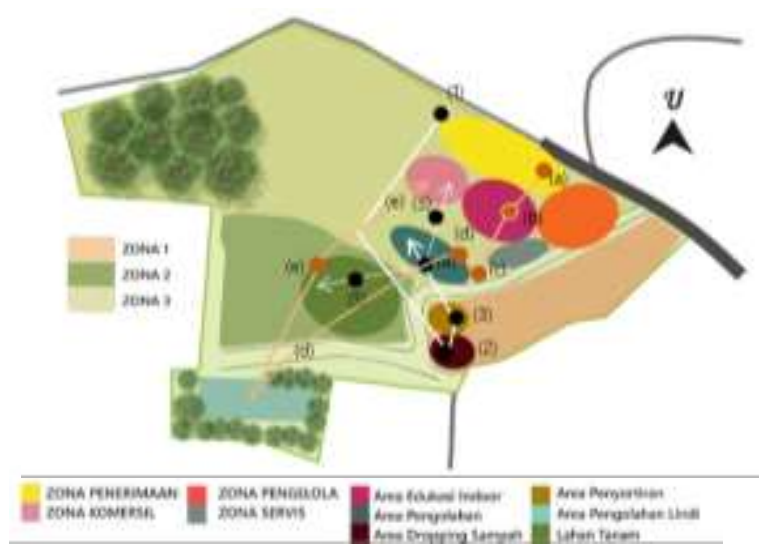

Gambar 3. Pemintakan Akhir Pada Tapak

\subsection{Analisis Sirkulasi}

Sirkulasi merupakan bagian penting dalam perancangan dengan penekanan desain sekuen ruang. Sirkulasi harus dapat mengarahkan pelaku menuju ruang-ruang yang ada sesuai dengan alurnya. 
1. Tujuan: Menentukan alur sirkulasi pada kawasan TPA Kaliori sesuai dengan alur pengolahan sampah.

2. Dasar pertimbangan: analisis pemintakan dan analisis tapak.

3. Proses analisis: menentukan sirkulasi kegiatan operasional pengolahan sampah mencakup sirkulasi kendaraan pengolahan sampah dan pekerja. Sirkulasi pengunjung wisata dirancang berdasarkan sirkulasi kegiatan operasional tersebut.

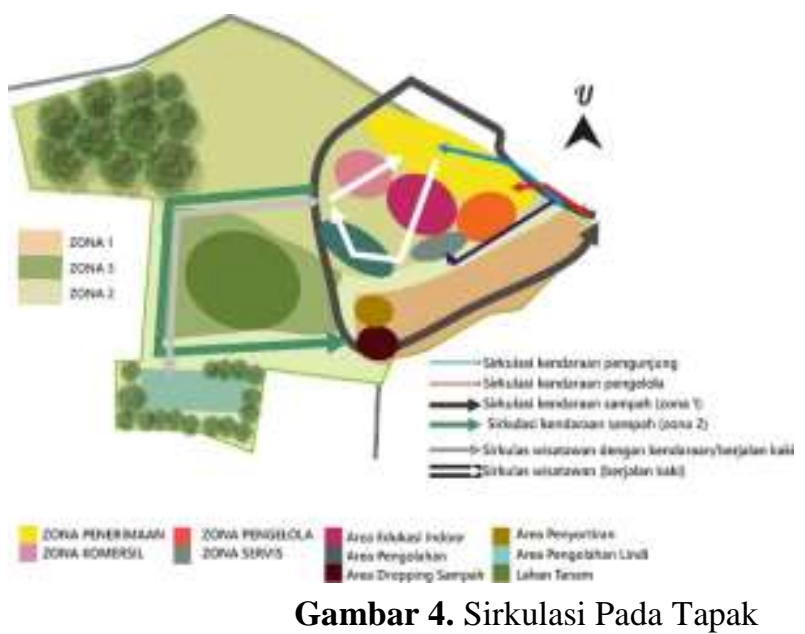

Pada Gambar 4, sirkulasi dibedakan menjadi sirkulasi kendaraan meliputi kendaraan pengangkut sampah, kendaraan pengunjung, kendaraan pengelola kendaraan dan sirkulai manusia meliputi sirkulasi pengunjung baik dengan berjalan kaki maupun menggunakan kendaraan wisata dan sirkulasi pengelola TPA. Antara bangunan dan bentang alam dihubungkan oleh plaza sehingga perpindahan antara ruang indoor ke ruang outdoor terasa mengalir. Plaza ini berfungsi sebagai tempat istirahat

\subsection{Analisis Bentuk dan Tampilan Bangunan}

Bentuk bangunan dipertimbangkan berdasarkan fungsi bangunan serta kondisi tapak dengan peletakan sesuai dengan pemintakan.

1. Analisis Orientasi Banguan Bangunanbangunan disusun menggunakan grid dengan arah orientasi mengikuti kontur pada tapak serta mengarah ke bangunan utama seperti yang terlihat pada Gambar

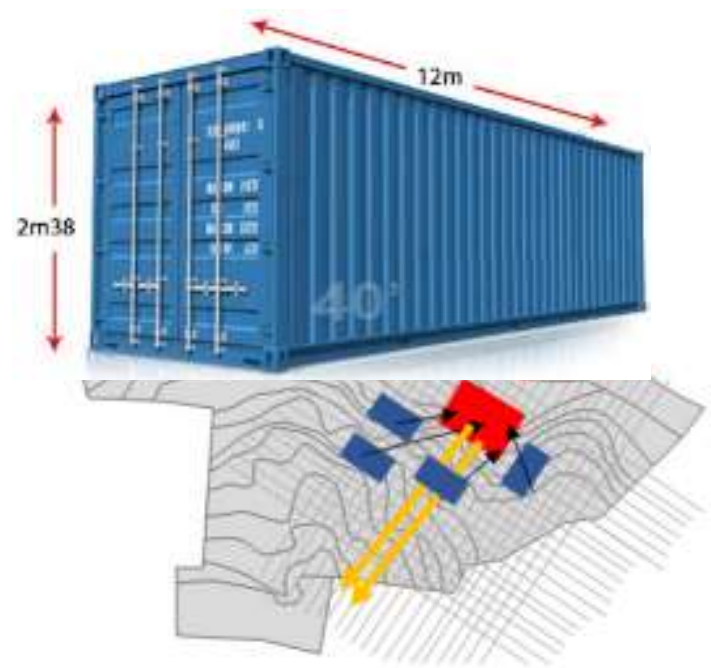

5.

Gambar 5. Penentuan Orientasi Bangunan

\subsection{Analisis Bentuk Bangunan}

Bentuk dasar bangunan menggunakan modul shipping container atau box peti kemas. Kontainer dipilih dengan pertimbangan:

1. menampilkan kesan daur ulang pada bangunan

2. memperkuat building image sebagai kawasan pengolahan sampah.

3. Dapat dibangun dengan sistem knock down dan mudah dipindahkan (portabel).

Modul kontainer yang dipakai adalah ukuran 40 kaki dan 20 kaki (Gambar 6). Modulmodul kontainer ditata dengan cara ditumpuk atau disejajarkan.

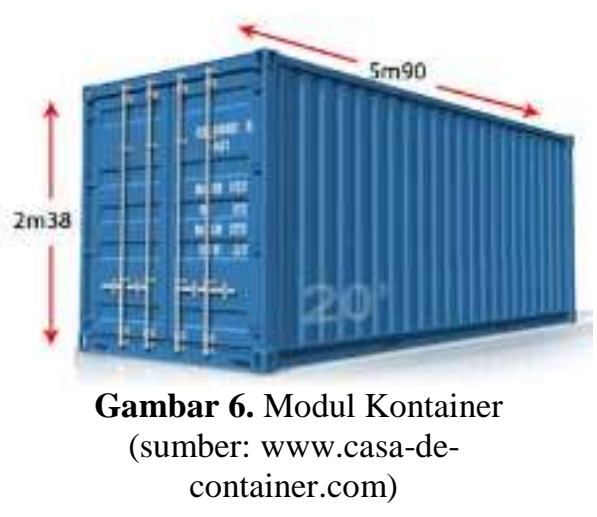




\subsection{Analisis Tampilan Bangunan}

Bangunan menampilkan kesan industrial dengan tujuan memperjelas fungsi TPA sebagai fasilitas pengolahan sampah.

Kontainer tidak digunakan pada semua bangunan dengan pertimbangan pemenuhan kebutuhan ruang masing-masing bangunan. Kontainer digunakan pada bangunan wisata dan penunjang wisata dan bangunan lain tidak menggunakan kontainer namun tetap memiliki kesan indutrial.

Material yang memperkuat kesan indutrial digunakan pada bangunan, di antaranya:

1. Kaca, diaplikasikan pada bagian bangunan yang memerlukan view yang luas seperti pada bangunan penerima dan cafe.

2. Bata ringan dan bata merah, iaplikasikan pada bangunan pengelola dan rumah kompos dengan pertimbangan kestabilan suhu dan dimensi ruang yang dibutuhkan.

3. Baja, memiliki sifat fleksibel dan kuat menahan beban tarik,

Baja digunakan sebagai rangka pada bangunan

4. Material isolator panas (Gambar 7), digunakan pada dinding dan atap bangunan yang menggunakan kontainer. Material insulator panas ini dapat menyediakan temperatur yang cenderung seragam di dalam ruang.

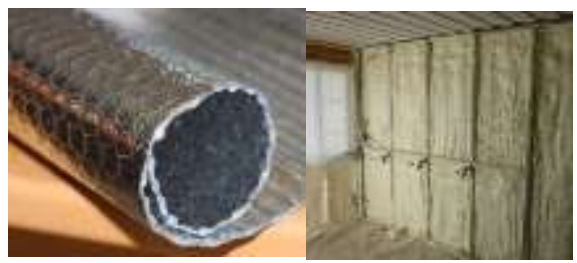

Gambar 7. Material Isolator Panas (sumber: ecomat88.com)

Material daur ulang juga diaplikasikan pada bangunan sebagai salah satu pembelajaran mengenai pengolahan sampah kepada pengunjung. Material daur ulang digunakan pada interior bangunan wisata. Material daur ulang yang digunakan dapat berupa ban bekas, koran bekas, maupun botol kaca dan plastik seperti terlihat pada Gambar 8.

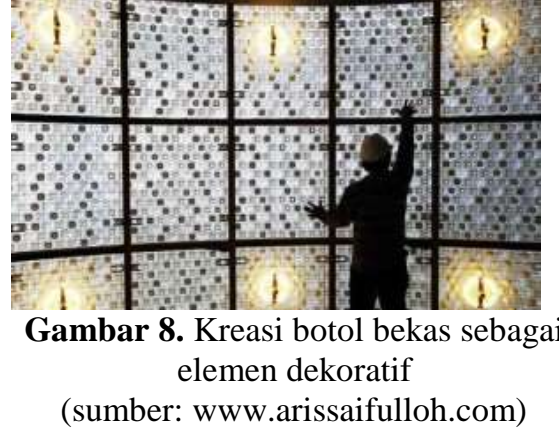

\subsection{Analisis Bentang Alam}

1. Tujuan: mendapatkan pola tata bentang alam yang berfungsi sebagai ruang terbuka hijau, penyelaras antara bentuk tapak dan massa bangunan, memudahkan sistem sirkulasi, serta sebagai area produktif (kebun organik).

2. Dasar pertimbangan: Mampu menunjang fungsi dan kegiatan di TPA dan menjadi nilai atraktif sebagai kawasan wisata edukasi.

3. Analisis:

Elemen bentang alam dibagi menjadi dua jenis yaitu:

a. Bidang lunak (soft scape), berupa vegetasi dengan jenis vegetasi peneduh, vegetasi pengarah, vegetasi penyejuk, vegetasi produktif, dan vegetasi ground cover.

b. Bidang keras (hard scape), berupa perkerasan yang menunjang kegiatan serta sirkulasi.

\subsection{Analisa Struktur}

Tujuan: mendapatkan sistem struktur yang sesuai dengan pembebanan.

Dasar Pertimbangan: beban yang harus didukung, kondisi tanah, bentuk bangunan, karakter bangunan, dan pengaruh terhadap lingkungan sekitar.

1. Super structure dan Sub structure Modul-modul bangunan kontainer disusun dengan struktur tumpuk (stacking system) dan dikunci oleh baut khusus. 
Gambar 9 menunjukkan detail dari sistem pengunci antar unit kontainer.

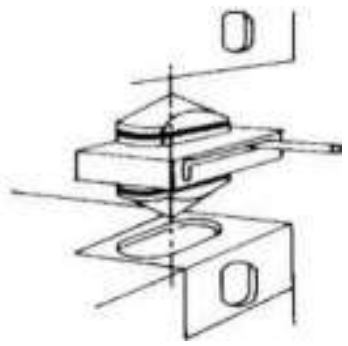

Gambar 9. Sistem pengunci antar kontainer

(sumber: www.globalsecurity.org)

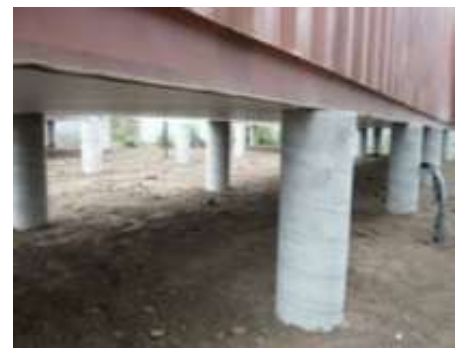

Gambar 10. Pondasi umpak pada bangunan kontainer (sumber: homeinabox.blogspot.com)

Sub structure yang diterapkan pada bangunan kontainer adalah pondasi umpak berbahan beton (Gambar 10), dengan peletakan di bawah titik pembebanan pada kontainer.

\section{Upper structure}

Pemilihan sistem struktur yang digunakan berdasarkan pertimbangan :

a. Kekuatan, keawetan, dan keamanan.

b. Fleksibel.

c. Kesesuaian dan respon terhadap iklim setempat.

Upper structure pada bangunan kontainer memiliki fungsi ganda, yaitu sebagai penutup bangunan dan sebagai secondary skin untuk bagian yang masih menggunakan atap asli kontainer. Atap sebagai secondary skin berfungsi untuk mengurangi panas karena atap kontainer terbuat dari logam. Atap sekunder ditopang dengan besi dan disambung dengan baut pada rangka utama kontainer.

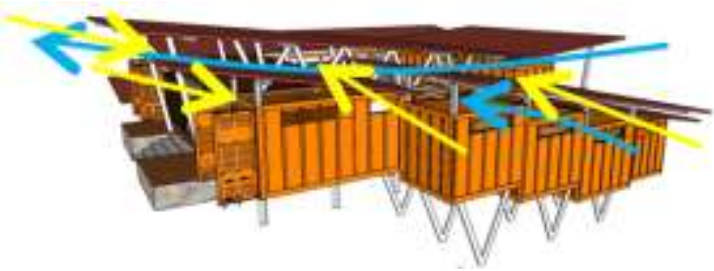

Gambar 11. Pencahayaan dan penghawaaan alami pada bangunan kontainer

Pada Gambar 11, ruang antara atap asli kontainer dan atap sekunder dimanfaatkan sebagai sirkulasi cahaya matahari untuk pencahayaan alami dan angin untuk penghawaan alami.

\section{KESIMPULAN (KONSEP DESAIN)}

TPA Kaliori dirancang sebagai fasilitas pengolahan sampah serta sebagai wisata edukasi yang menekankan pada pengolahan sekuen ruang berdasarkan urutan proses pengolahan sampah. Ruang-ruang dihubungkan oleh sirkulasi yang secara otomatis akan membimbing penggunanya untuk mengikuti sebuah urutan. Pengolahan dan penataan peruangan dapat dilihat pada Lampiran

Nama : TPA Kaliori

Lokasi : Desa Kaliori, Kalibagor, Kabupaten Banyumas

Luas Lahan $\quad: \pm 32.000 \mathrm{~m}^{2}$

Luas Bangunan $: \pm 2557,3 \mathrm{~m}^{2}$

Daya Tampung : Pengolahan sampah: 3 ton/hari Pengunjung: 150 orang/hari

Kegiatan : Fasiltas pengolahan sampah dan wisata edukasi 


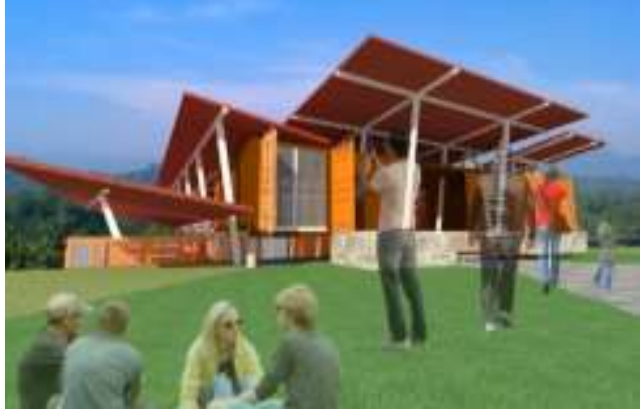

Gambar 12. Waste Edu Centre

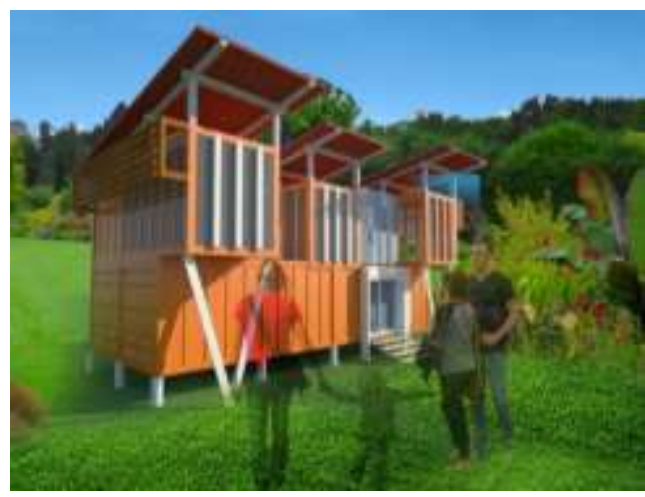

Gambar 13. Kaliori Shop

Gambar 12 merupakan Waste Edu Centre sebagai bangunan penerima, dan Gambar 13 merupakan Kaliori Shop yang berfungsi sebagai display dan penjualan produk hasil pengolahan sampah. Kedua bangunan tersebut menggunakan modul kontainer dengan building image bangunan industrial.

Gambar 14 merupakan plaza sebagai area penerimaan bagi pengunjung wisata edukasi. Gambar 15 merupakan plaza penghubung antar bagian dari organic cafe.

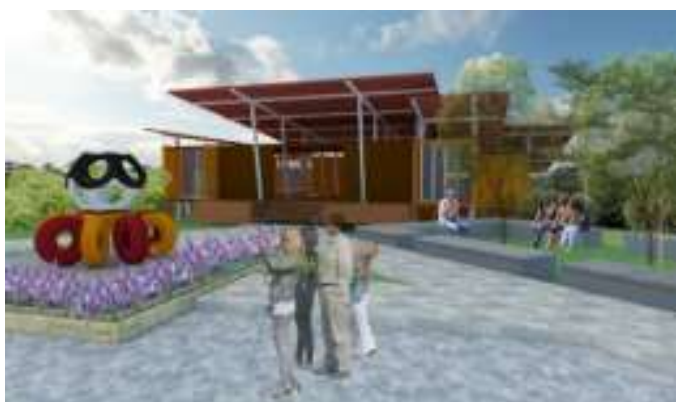

Gambar 14. Plaza Penerima

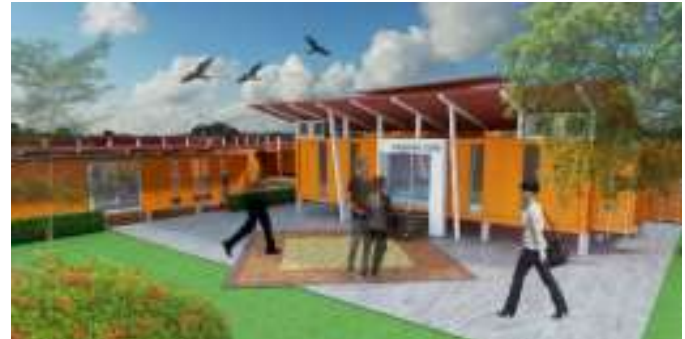

Gambar 15. Plaza Pada Organic Cafe

Pengunjung dapat menempuh perjalanan wisata edukasi dengan berjalan kaki maupun menggunakan kendaraan wisata (untuk bagian tertentu) seperti yang terlihat pada Gambar 16.

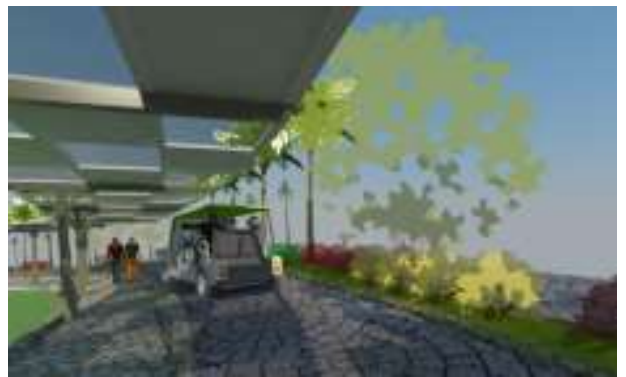

Gambar 16. Jalur Pedestrian dan Kendaraan Wisata

\section{REFERENSI}

Damanhuri, Enri. 2008. Diktat Landfilling Limbah. FTSL ITB

www.sanitasi.net

liputan6.com 


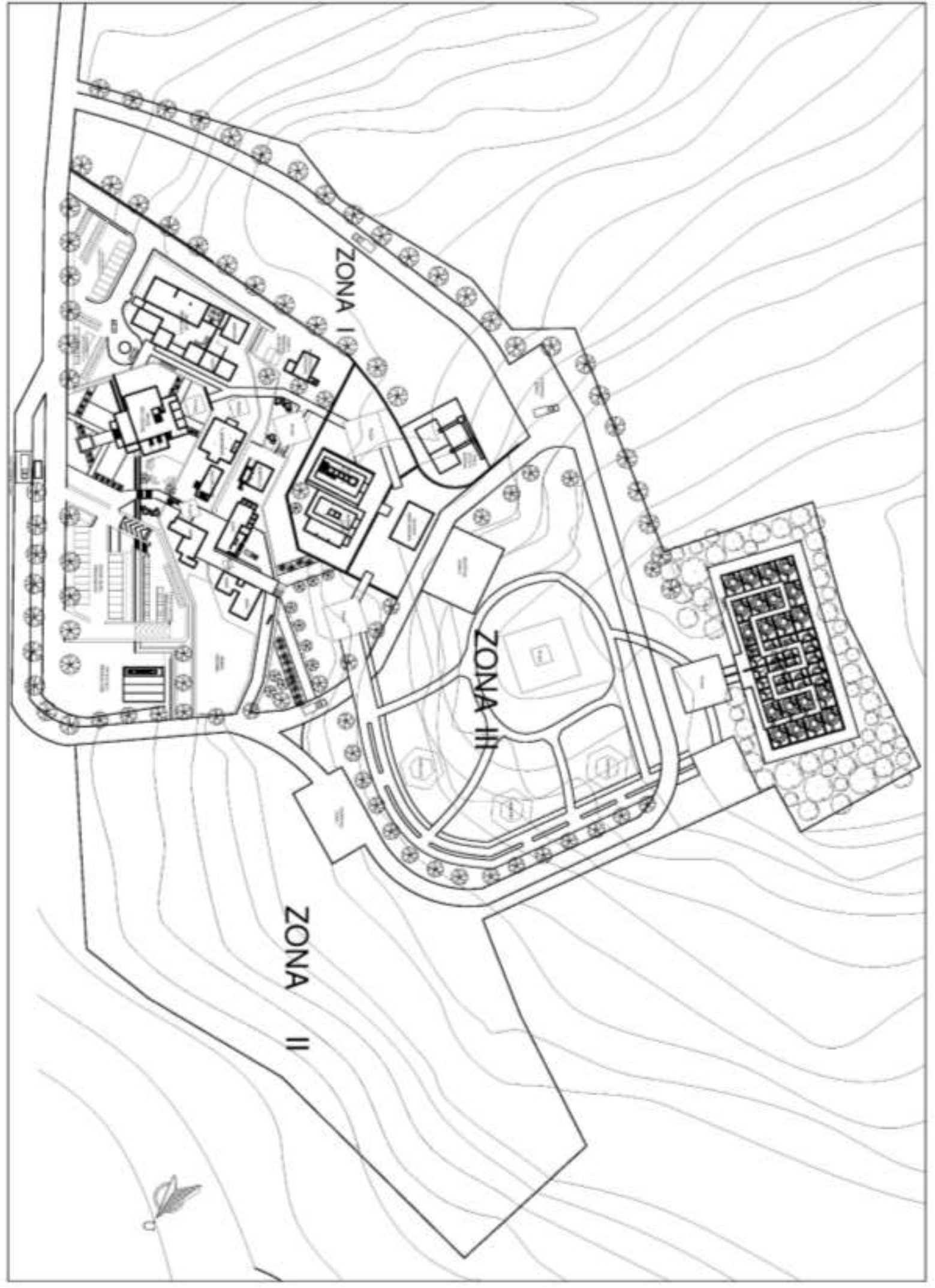

Lampiran 1. Rencana Tapak 